\title{
Nanocomposite coatings in polymeric matrices and their effect on friction coefficient
}

\author{
Jan Novotný ${ }^{1, *}$, Irena Lysoňková ${ }^{1}$, Milan Sapieta ${ }^{2}$ \\ ${ }^{1}$ J.E Purkyně University in Ústí nad Labem, Faculty of Mechanical Engineering, Ústí nad Labem, \\ Czech Republic \\ ${ }^{2}$ University of Žilina, Faculty of Mechanical Engineering, Univerzitna 1, 010 26, Žilina, Slovak \\ Republic
}

\begin{abstract}
This paper deals with possibilities of production of new nanocomposite coatings in polymer matrix on aluminium alloys, namely the formation of a composite coating in a polymer matrix on an aluminium alloy. It is a PMMA coating (polymethylmethacrylate) with the addition of $\mathrm{TiO}_{2}$ particles. Working with these particles requires not only safety but also a suitable preparation process to obtain particles of suitable size, their subsequent homogeneous distribution in the coating (particles of this size are influenced by electro statically attractive forces and have a strong tendency to aggravate).The aim is to determine if the coatings will affect the surface's condition and its properties. The focus of the work is on selecting of the appropriate preparation of sample technology, examining the particle distribution in the coating and the effect of the coating on the coefficient of shear friction. Consequently, what can be achieved is the coefficient of shear friction of the surface of the coated part compared to the uncoated surface (at different particle concentrations in the spin) and the distribution of $\mathrm{TiO}_{2}$ particles on the surface of the sample.
\end{abstract}

Keywords: Nanocomposite coating, polymer, coefficient of friction, surface analysis.

\section{Introduction}

The usage of polymeric materials as a matrix for nanocomposite materials has become a frequent case. This is mainly due to their features and availability. It is important to keep in mind the size of the nanoparticles used and their amount in the matrix. The aim of the research is to investigate the possibility of forming PMMA matrix nanocomposite coatings. An influencing factor is particle selection and coating technology. For evaluation, it is important to measure and analyse the resulting coatings. Therefore, shear friction coefficient by tribometric assays and particle size distribution in electron microscopy will be tested.

\footnotetext{
* Corresponding author: jan.novotny@ujep.cz

Reviewers: Róbert Čep, Mária Čilliková
} 


\section{Used materials}

\subsection{Characteristics of the underlying material}

The base material, which is the material on whose surface we form the coating, is the Al-Si alloy. The base material was obtained from previous research of metal forms designed especially for the production of tires. These metal molds are made of Al-Si alloys.

\subsection{Matrix material}

Polymethyl methacrylate (PMMA) was selected as the matrix material. It is an amorphous thermoplastic with perfect light transmission. Due to the chemical composition, it is a polar plastic that has excellent mechanical properties. It has a wide range of applications, especially in the automotive and construction industries. The modulus of elasticity reaches up to $3200 \mathrm{MPa}$. [1-4]

\subsection{Reinforcement material}

Titanium dioxide $\left(\mathrm{TiO}_{2}\right)$ was chosen as the reinforcement material of the nanocomposite coating. It is very suitable for coating for its properties in nanoparticle scale. Its material of high hardness is antistatic and is resistant to mechanical wear. [5-7] It has a high refractive index and is just like PMMA UV resistant. $\mathrm{TiO}_{2}$ nanopowder from the previous research was used. $\mathrm{TiO}_{2}$ was milled as a nanopowder by a planetary ball mill. [8-11]

\section{Nanocomposite coating preparation}

As a matrix for the nanocomposite coating, polymethylmethacrylate (PMMA) was used, which is available to buy in the form of plates. Titanium dioxide $\left(\mathrm{TiO}_{2}\right)$ in the form of a milled nanopowder was used as reinforcement.

A solution method was chosen for the preparation. As the PMMA solvent, chloroform $\left(\mathrm{CHCl}_{3}\right)$ was chosen.

Table 1. Labelating of created samples

\begin{tabular}{|c|c|c|c|}
\hline \multicolumn{2}{|c|}{ Solution dilution - 1:10 } & \multicolumn{2}{c|}{ Solution dilution - 1:10 } \\
\hline \multicolumn{2}{|c|}{ Application Method - dipping } & \multicolumn{2}{c|}{ Application Method - by brush } \\
\hline Sample & Concentation of $\mathrm{TiO}_{2}[\%]$ & Sample & Concentation of $\mathrm{TiO}_{2}[\%]$ \\
\hline 1A & 0 & $1 \mathrm{C}$ & 0 \\
\hline 2A & 0.01 & $2 \mathrm{C}$ & 0.01 \\
\hline 3A & 0.1 & $3 \mathrm{C}$ & 0.1 \\
\hline 4A & 1 & $4 \mathrm{C}$ & 1 \\
\hline \multicolumn{2}{|c|}{ Solution dilution - 1:3 } & \multicolumn{2}{c|}{ Solution dilution - 1:3 } \\
\hline Application Method - dipping & Sample & Concentation of $\mathrm{TiO}_{2}[\%]$ \\
\hline Sample & Concentation of $\mathrm{TiO}_{2}[\%]$ & 1D & 0 \\
\hline 1B & 0 & 2D & 0.01 \\
\hline 2B & 0.01 & 3D & 0.1 \\
\hline 3B & 0.1 & 4D & 1 \\
\hline 4B & 1 & \multicolumn{2}{c}{} \\
\hline
\end{tabular}

The final coating solution was already applied to samples of the backing material. Two coating methods were chosen: first being the dipping method, which consists in submerging the prepared backing material into the coating solution. The second method was the brush 
application method. Brush dipped in the coating solution and such is apply it to the substrate. The resulting coating is allowed to dry at room temperature.

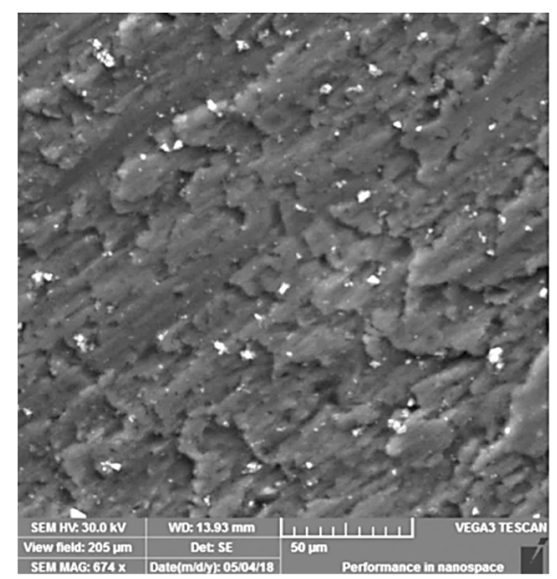

Fig. 1. Sample 4A coated by dipping method in a solution diluted 1:10

Figure of the sample 4A (Figure 1) shows that the higher titanium dioxide concentrations in the coating $(1 \%)$ by the chosen coating method - by dipping in a solution diluted 1:10, i.e. the same coating and dilution method as in all samples marked as A, it results in a better distribution of the particles in the coating. However, there are still areas with accumulated dust particles in the coating. Care must be taken to ensure that the environment is clean.

\section{Research tools - Tribometric assays}

It was necessary to analyse the examined coatings for the evaluation. The coefficient of shear friction of the coated surfaces was tested by tribometric assays.

Measurement of the friction coefficient was performed by the universal tribometer Bruker UMT Tribolab. We used a two-axis power sensor with a maximum load of $1000 \mathrm{~N}$ and $50 \mathrm{~N}$. Input values:

- Tribometer Body - ball ø $10 \mathrm{~mm}$

- Track length $x=20 \mathrm{~mm}$

- Velocity $v=10 \mathrm{~mm} \cdot \mathrm{s}^{-1}$

- Measuring time $t=60 \mathrm{~s}$

- Load force $F_{z}=5 \mathrm{~N}$

\section{Results of the Measurement}

The usage of polymeric materials as a matrix for nanocomposite materials has become a frequent case. This is mainly due to their features and availability. It is important to keep in mind the size of the nanoparticles used and their amount in the matrix. The aim of the research is to investigate the possibility of forming PMMA matrix nanocomposite coatings. An influencing factor is particle selection and coating technology. For evaluation, it is important to measure and analyse the resulting coatings. Therefore, shear friction coefficient by tribometric assays and particle size distribution in electron microscopy will be tested. 
Table 2. Measured coefficients of friction

\begin{tabular}{|c|c|c|}
\hline Sample & Coefficients of friction & Standard deviation \\
\hline Sample without coating (SO) & 0.1216 & 0.00898 \\
\hline
\end{tabular}

Table 3. Measured coefficients of friction $1 \mathrm{~A}-4 \mathrm{~A}$

\begin{tabular}{|c|c|c|c|}
\hline Sample & Concentation of $\mathrm{TiO}_{2}[\%]$ & Coefficients of friction & Standard deviation \\
\hline $1 \mathrm{~A}$ & 0 & 0.3788 & 0.03119 \\
\hline $2 \mathrm{~A}$ & 0.01 & 0.3812 & 0.03796 \\
\hline 3A & 0.1 & 0.4075 & 0.03773 \\
\hline 4A & 1 & 0.4076 & 0.04143 \\
\hline
\end{tabular}

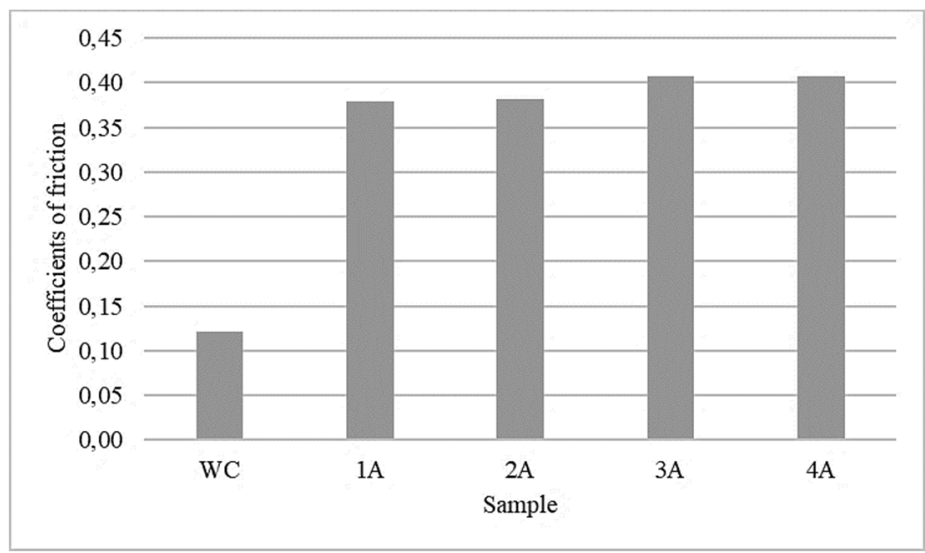

Fig. 2. Comparison of measured coefficients of friction (A)

The friction coefficient values measured in samples 1A to 4A are compared in Figure 2. There is well visible a jump increase in the coefficient of friction coefficient value of coated samples over a non-coated sample. Furthermore, a slight increase in the friction coefficient value can be observed with the increasing concentration of titanium dioxide in the coating.

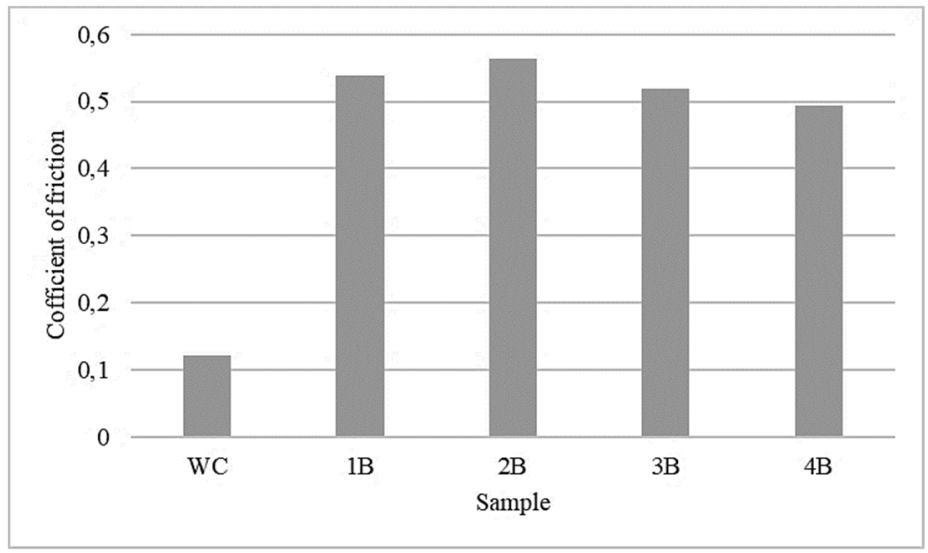

Fig. 3. Comparison of measured coefficients of friction (B)

The friction coefficient values measured in samples $1 \mathrm{~B}$ to $4 \mathrm{~B}$ have the highest increase. Its value is almost fivefold compared to the uncoated sample. It can be seen from Figure 3 that the increase is remarkable for all coated samples. However, the rule does not be applied to the increasing coefficient of friction with the increasing percentage of titanium dioxide. 
Table 4. Measured coefficients of friction $1 \mathrm{C}-4 \mathrm{C}$

\begin{tabular}{|c|c|c|c|}
\hline Sample & Concentation of $\mathrm{TiO}_{2}[\%]$ & Coefficients of friction & Standard deviation \\
\hline 1C & 0 & 0.3876 & 0.03998 \\
\hline 2C & 0.01 & 0.4147 & 0.03768 \\
\hline 3C & 0.1 & 0.4155 & 0.04208 \\
\hline 4C & 1 & 0.4166 & 0.05153 \\
\hline
\end{tabular}

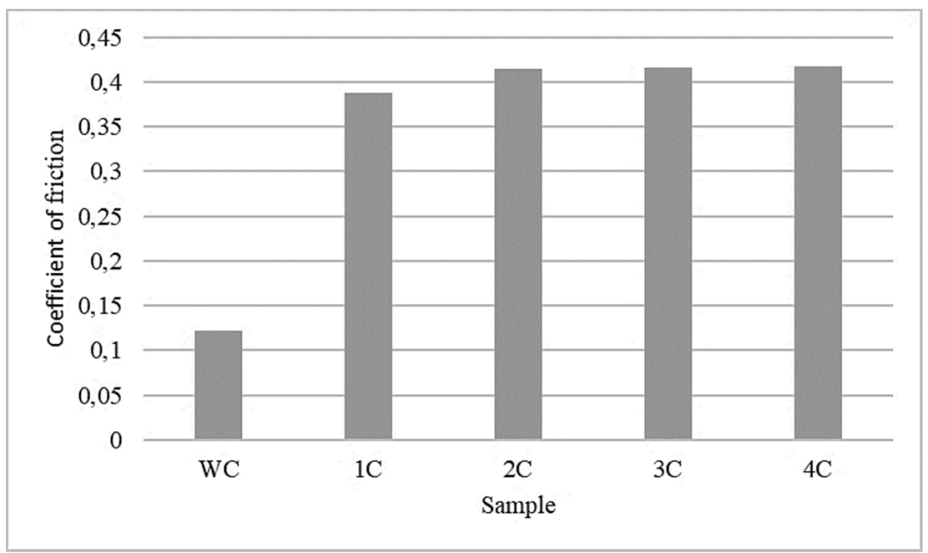

Fig. 4. Comparison of measured coefficients of friction (C)

For samples marked $1 \mathrm{C}$ to $4 \mathrm{C}$ also applies the jump increase of the coefficient of friction value. Here we can observe a slight increase in the coefficient of friction and the increasing percentage of titanium dioxide in the coating. The highest coefficient of friction is thus on the sample 4C, which is also observable in Figure 4.

Table 5. Measured coefficients of friction 1D - 4D

\begin{tabular}{|c|c|c|c|}
\hline Sample & Concentation of $\mathrm{TiO}_{2}[\%]$ & Coefficients of friction & Standard deviation \\
\hline 1D & 0 & 0.4733 & 0.04683 \\
\hline 2D & 0.01 & 0.4909 & 0.04756 \\
\hline 3D & 0.1 & 0.4935 & 0.05142 \\
\hline 4D & 1 & 0.4941 & 0.06319 \\
\hline
\end{tabular}

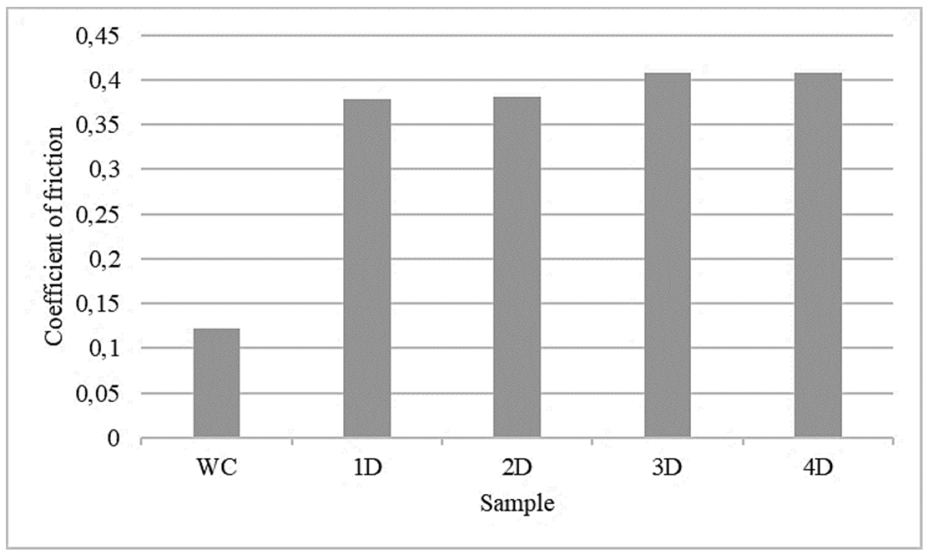

Fig. 5. Comparison of measured coefficients of friction (D) 
The friction coefficient values measured in the 1D to 4D samples show again a stepwise increase in the friction coefficient of the coated samples compared to the uncoated sample. It can be seen in Figure 5 that the greatest friction coefficient is for sample $4 \mathrm{D}$ is. The increase is approximately four times the coefficient of friction of the uncoated material. It is also a valid phenomenon that increasing the percentage value of titanium dioxide increases the coefficient of shear friction.

\section{Conclusions}

The aim of the experiment was to evaluate the measured friction coefficients of the coated samples and their comparison with the uncoated sample. It was important to choose the kind of added reinforcement particles in the matrix. Several variants of the concentrations of the added particles were also tested in the coatings, namely titanium dioxide particles. There were prepared two variants of dilution of the coating solution and the technology of its application to the underlying material.

Measurement of the friction coefficient produced an expected and targeted finding that the coated samples exhibited a jump increase in the coefficient of friction versus uncoated samples. On the frame of the three variants of the coated samples, there is a link between the increasing $\mathrm{TiO}_{2}$ concentration and the friction coefficient value. For all samples $\mathrm{A}, \mathrm{B}, \mathrm{C}, \mathrm{D}$, more than three times the coefficient of friction was measured compared to uncoated samples. A new beneficial finding in general is that the highest coefficient of friction in coated samples was found in samples with the highest $\mathrm{TiO}_{2}$ concentration, it means with concentration $1 \%$ of $\mathrm{TiO}_{2}$ in polymer matrix.

\section{References}

1. L. Běhálek, Polymery. [online], https://publi.cz/books/180/18.html

2. J. Krzak, J. Filipiak, C. Pezowicz, A. Baszczuk, M. Miller, M. Kowalski, R. Będziński, The effect of substrate roughness on the surface structure of TiO2, SiO2, and doped thin films prepared by the sol-gel method. Acta of Bioengineering and Biomechanics, vol. 11, nr 2, 21-29 (2009)

3. Čuboňová, N. - Císar, M. Design of camera mount and its application for monitoring machining process. Advances in Science and Technology, Research Journal, 9(26), 2015, 34-40.

4. J. Petru,T. Zlamal, R. Cep, D. Stancekova, M. Pagac, O. Vortel, Mechanisms of cutting insert wear and their influence on cutting ability of the tool during machining of special alloys. Conference: 3rd International Conference on Manufacturing Engineering and Technology for Manufacturing Growth (METMG 2015), Canada 36-40 (2015)

5. R. Horký, Návrh nanokompozitnich povlaků v polymerní matrici a jejich vliv na vlastnosti povrchu. Univerzita J. E. Purkyně v Ústí nad Labem, Ústí nad Labem, (2018)

6. M. Novák, N. Náprstková, The influence of cutting conditions on surface roughness during steel X38CrMoV5 grinding. Key Engineering Materials 581, 247-254 (2014).

7. P. Valášek, R. D'Amato, M. Müller, A. Ruggiero, Mechanical properties and abrasive wear of white/brown coir epoxy. Composites Part B. Engineering 146, 88-97 (2018)

8. J. Novotný, M. Jaskevič, J. Cais, T. D. Hung, The shape and structure of titanium dioxide nanoparticles. In Manufacturing Technology, Vol. 16, No. 5, pp. 1102-1106 (2016) 
9. T. Hanes, P. Hvizdoš, M. Ťavodová, D. Kalincová, J. Hricová, P. Beňo, Coating surface roughness measurement made on coining dies, Manufacturing technology : journal for science, research and production. - ISSN 1213-2489. - Vol. 14, no. 3, 309-317 (2014)

10. Stanček, J., Bulej, V. Design of driving system for scissor lifting mechanism. Academic journal of manufacturing engineering. 13(4), 38-43 (2015)

11. J. Zapoměl, V. Dekýš, P. Ferfecki, A. Sapietová, M. Sága, M. Žmindák, Identification of material damping of a carbon composite bar and study of its effect on attenuation of its transient lateral vibrations. Int. Journal of Applied Mechanics 7 (6), (2015) 